\title{
Research of Group Dynamics in Training of Corporate Culture Formation
}

\author{
Anastasiya Pesha*, Olga Koropets, and Maria Plutova \\ Ural State University of economics Yekaterinburg, Russia
}

\begin{abstract}
In the article we present the results of the research of group dynamics in the training of corporate culture. The object of the research is the group dynamics as a set of processes that take place in the group of training participants during its operation. The subject of the research is the possibility of managing the group dynamics of the student group during the training of corporate culture formation. We have put forward a hypothesis of the study that in the case of considering the formation of corporate culture of the student group indicators group dynamics in the training construction, it is possible to form a cohesive group, whose members accept common values and norms of behavior, focused on achieving a common goal and are capable of self-government. The following methods were used in the study: content analysis, training; survey methods, observation - for the analysis of the results. During processing of the research results, the authors used methods of descriptive analysis in the calculation of averages and standard deviations in confidence-mistrust, correlation and regression analysis and analysis of variance in the evaluation of changes in the indicators of group dynamics and components of corporate culture groups after the training.
\end{abstract}

\section{Introduction}

Social psychology has recently become increasingly involved in solving organizational problems. The issues of group dynamic processes of construction, coordination, development and maintenance of intra-group and intergroup relationships attract great interest. The economies of countries are growing, new and more complex tasks are emerging that require modernization of organizational processes at all levels.

Modern science has accumulated extensive experience in the study of group dynamics. Among the foreign researchers of the issues of group structure and dynamics, the authors can mention such authors as Bales R. F., Cartwright D. \& Zander A., Davis D., Leinhardt S. [1, 2, 3]. Prominent Russian scientists also made a significant contribution to the development of governance of intragroup relations: A. V. Petrovsky, G. M. Andreeva, R. L. Grechesky, A. I. Dontsov, L. I. Umansky, A. I. Zhuravlev, D. V. Olshansky, I. A. Ilyin, V. V. Boyko, J. L. Kolomensky and others $[4,5,6]$.

Management issues of the structure and dynamics of collective higher education are considered in a large number of modern research. The study of the problems of development of the modern student and student groups can be found in works of L. I. Anniversary, L. I. Umansky, A. S. Chernisheva, B. S. Volkova, V. S. Margun, T. I. Artemieva, and others [1, 7, 8].

A large number of modern studies are devoted to the application of the training interaction as a means of formation of competences of students in higher educational institutions: among them there are works of N. I. Nikitina, Grebennikova V.M., Sedina V.I., Haptseva I.A., Dyachkova A.E. Grebenik L. G., Ledovskoy M.E., Kovaleva O.A., Pyatibratov B., Scheinbaum V. S. and others $[9,10,11]$.

Use methods of team work in the educational process recently a subject of many studies: V. I. Ekimova, Gansuar Christian, Neretina E. A., Korokoshko Yu. B., Baeva L.V., Plotnikova N. F. J. Staggers, S. Garcia, E. Nagelhout, G. Bloom , D. Stevens , T. Wickwire, G Bloom, D. Stevens , Larry K. Michaelsen, Michael Sweet and others [8, 12, 13, 14, 15, 16,17,18].

Corporate and organizational culture of the student environment and student groups is studied in the works of authors such as A.N. Palma, D. A. Vlasova, S. D. Reznik, M. V. Chernikovskaya, M. A. Nazarenko, V. G. Kamburg, Chizhikova E. S., Zhang X., De Pablos P. O., Xu Q [19, 20, 21].

The relevance of our research is determined by the fact that senior students, despite the long period of intragroup interaction in the educational process, the level of formation of the components of corporate culture and group dynamics are objectively assessed as unsatisfactory. This fact is explained by the high level of individualism and the lack of team orientation in learning, as well as the low level of development of communication skills of students, which is described in detail in earlier studies of the authors. In addition, the relevance of the study is confirmed by the increasing attention to the use of training forms of interaction in the educational process of higher education, as well as the effectiveness of training as a tool for managing group dynamics. 
The aim of the research is theoretical justification and empirical study of group dynamics in the training of corporate culture formation.

To achieve this goal, we formulated the following tasks:

1. To carry out the theoretical analysis of representations of a problem of group dynamics management in training based on studying of the domestic and foreign scientific literature.

2. To create a methodological apparatus for measurement of group dynamics.

3. To study the peculiarities of group dynamics in the student group during the training of corporate culture formation.

4. To develop and implement a training program for the formation of corporate culture of the student group, taking into account the methodology of group dynamics management.

5. To trace group dynamics in the course of realization of training of formation of corporate culture.

\section{Theoretical and methodological bases of research of group dynamics in training of formation of corporate culture of student group}

In modern literature, the term "training" is interpreted quite differently, which is associated with a wide range of training groups themselves [6, 22 and others].

After analyzing a number of approaches to the interpretation of the concept of "training", it can be argued that this is one of the methods that are used in teaching, psychocorrection and psychotherapy as a means of influencing the experience, the development of competencies, social attitudes and interpersonal interaction. The range of issues that are solved in the course of trainings is wide and there are different forms of them.

After analyzing a number of definitions, in the framework of our study, we will understand the "group dynamics" as socio-psychological processes that are based on the specifics of social interaction of group members.

In modern views on the process of group dynamics of scientists and practitioners in psychology, there are several classifications of stages of group dynamics [22, 23].

Since at the time of starting the work with students, the groups had been already permanent and carried out joint activities for a period of 2 years, the classification, including the stage of orientation (formation), confrontation, the "latent phase" (phase of cooperation) and the phase of integration in this study, can not be applied. The phase of orientation and formation was passed by the students in the first year of joint training.

We have characterized the stages of group dynamics in the training of corporate culture formation below, according to the classification proposed by $H$. E. Ravikovich [22].

1.Stage of recognition, of "grinding".

At this stage, a group of students develops group rules and norms of behavior. Despite the fact that students interact with each other for quite a long period, they do not need to develop group skills and rules. Of course, there are certain rules, formed in the group unconsciously, identified by us in the course of the study: for example, the attitude to the academic discipline (groups of 4 courses have a free attitude to the academic discipline, students often allow themselves to be absent from a number of classes, due to the combination of work and training; group 3 course - on the contrary, enshrines the rule of compulsory attendance in the classroom, group 2 course - has not developed general rules for discipline). However, the existing rules are understood and accepted by a smaller part of the students. So at this stage of group dynamics, it is very important to identify and consolidate them for a more successful passage of the next stages.

In addition to the group rules of training interaction, which are set by the group together with the leaders (sincerity, activity, rule "stop", confidentiality, "here and now" and others), which help to successfully adapt to the conditions of training, it is necessary both from the viewpoint of the corporate culture of the group and from the viewpoint of increasing the level of power of attorney of relations in the group to develop rules and norms of group interaction outside the training.

2.The stage of allocation and assignment of roles in the group.

At this stage, there is acceptance of group norms by group members, as well as consolidation of roles in the group.

At this stage, the participants of the training are involved in active interaction, find out the place in the group. There is an identification of group roles.

3. The stage of development, consolidation and optimization of schemes of interaction between team members.

At this stage, the group must be given the most difficult tasks. In the training of corporate culture at this stage, we conduct coaching group values, followed by their visualization as part of the competition for the best visualization of group values.

4. The stage of integration and successful work of the formed team. At our training, at the stage of integration, the group members consciously act within the framework of the rules and norms of behavior adopted in the group. The group is self-governing.

Within the training, we considered the student group as a form of uniting people to perform joint activities within the overall structure of the University, performing the function of learning and solving the problem of setting the goal of learning and choosing an educational path, meeting the requirements and norms of the selected educational direction. Therefore, in the training we are talking about the formation of a corporate (linking and uniting) culture of the student group, which is a subculture in relation to the corporate culture of the University.

Thus, within the framework of the training of corporate culture formation, we: translate the corporate culture of the University, form the internal culture of the student group, as well as develop the competence of students in the management of the corporate culture of the organization.

In this work, we focus on the formation of the internal culture of the group and the broadcast of corporate culture of the University as a tool for the formation of group dynamics, on the one hand, and the formation of group 
dynamics as a factor in the development of corporate culture - on the other. There is relationship between the key indicators of group dynamics and the components of corporate culture. An organizational component (Oc) includes indicators of adoption of corporate culture of the University student group; a value-emotional component $(\mathrm{VEc})$ - indicators of trust/distrust and cohesion of the student group; a reflective component (Rc) commitment, goal-setting and involvement; an activity component (Dc) includes indicators of adoption of group norms of behavior and interaction. When managing group dynamics, the group develops corporate culture. The higher the values of the components of the corporate culture, the closer the stage of integration and success of the group.

The training of corporate culture in student groups is collaborative and promotes active involvement of students in the training process, while creating a safe educational environment. Participation of students in the team interaction in the formation of corporate culture of the group contributes to a deeper understanding of the material of the discipline. In addition, during the training, students form the competence for independent cultural events in the future professional activities of specialists in personnel management.

\section{The study of group dynamics of the student group in the training and formation of corporate culture}

Sample/ Participants: in the training of corporate culture Sample/Participants: in the training of corporate culture carried out in the implementation process of discipline "Organizational culture" was attended by four student groups 4 (A), 3 (b). The total number was 55 students, and students of the 2 (C) course, who did not receive training in the control group - $23(\mathrm{~A} 1=16, \mathrm{~A} 2=15$; $\mathrm{B} 1=11, \quad \mathrm{~B} 2=12 \quad \mathrm{C} 1=11, \quad \mathrm{C} 2=12), \quad 69$ females (Nwomen=69), 9 male $(\mathrm{Nmen}=9)$. At the time of the training, the participants had already studied the theoretical foundations of corporate culture management of the organization and were ready to apply the acquired knowledge in practice, to develop their managerial competencies and skills of team interaction.

Materials: we used the author's program of training of corporate culture formation of Pesha A.V., adapted for work with student groups [24].

Evaluation of results. The results were evaluated by a number of methods: author's questionnaire by Pesha A.V. to assess the perception of corporate culture of the University student group [24]. This questionnaire highlights 4 components of corporate culture: organizational, value-emotional, reflective and activity, which give a comprehensive picture of the existing at the time of the survey culture of the student team. Methods of assessment are "Trust-distrust of the student to the group" (based on the technique by Kupreychenko A. B) [25]. In addition, the method of observation was used in identifying leadership in the group (based on the profile of competencies of the leader), the distribution of team roles. When processing the results of the study, the methods of descriptive analysis were used in the calculation of averages and standard deviation for confidence-mistrust, correlation and regression analysis of confidence-mistrust and variance analysis in the evaluation of changes in the indicators of group dynamics and components of the corporate culture of groups after the training. Program: the training program was designed for 18 hours.

The following was done to manage the group dynamics in the training:

1. During the training, students had a free choice in the formation of small working teams.

Based on the analysis of the study conducted by Chapman K. with co-authors [26], as well as awareness of the fact that the 3 and 4 courses had respectively different subcultures and informal groups, we concluded that students' independent choice of team members for group interaction will affect more positively on the process and the results of group work. To confirm the conclusion, we formed groups on a random basis at the initial stages of work, that is, we divided students into groups with the help of elementary calculation techniques. The study showed that self-selected groups of students allowed improving the results in respect of all studied variables. In particular, students who could communicate better with each other, showed more enthusiasm about working in the group, more interest in their group, better coped with emerging intra-group differences, were more focused on group achievements.

The work was carried out in small groups with a different number and almost at all stages of the work ended with a group-wide interaction and general feedback, which makes it possible for each student to equally express themselves and "choose one's team". At the same time, watching the independent choice of students to work in small groups, we noted the change in the composition of their participants in the independent choice of students during the first training day. On the second day of the training, the composition of small groups became more stable. Analyzing the composition of groups in terms of academic performance of students, we concluded that the choice of partners for cooperation in less than $40 \%$ of cases is based on the level of performance, the team students gathered with different levels of knowledge and performance, the criterion of friendly relations played a more important role.

2. During the group project work, students had the opportunity to exchange ideas and opinions with members of other small groups. This aspect is important because the goal of our work is not to form subcultures within the student groups, but to come to the acceptance by the majority of the members of the group of generally accepted values, goals and norms of interaction, the development of competences of teamwork.

3. The focus of the group work was on the development of trust relations. Starting with the confidence of the group members themselves, members of their group and the teacher, as the leader of the training and the head of the educational process.

To assess the "trust - distrust" in the group, we took as a basis the questionnaire by Kupreychenko A. B. "Assessment of trust/distrust of employees to colleagues and managers of the organization", reorienting the issues in line with the assessment of trust relationships within the student group [25]. The technique allows determining the main criteria for people in the group: reliability, unity and knowledge, the tendency to replace trust with faith or 
calculation, the degree of ambivalent attitude to classmates.

During the correlation and regression analysis of the values of indicators in groups before and after the training on the formation of corporate culture on the criteria of trust and distrust, the following results were obtained, demonstrating the positive dynamics of changes in trust and group cohesion as an indicator of group dynamics and the statistical significance of the data, showed in table 1 .

Table 1. Reflection of the shift in the evaluation based on the confidence-distrust criteria in the student groups after the implementation of the training.

\begin{tabular}{|l|c|c|c|c|c|c|}
\hline criterion & A1 & A2 & B2 & B3 & C1 & C2 \\
\hline reliability & 0.2 & 0.5 & 0.4 & 0.6 & 0.1 & 0.3 \\
\hline unity & 0.5 & 0.8 & 0.2 & 0.5 & 0.1 & 0.2 \\
\hline knowledge & 0.2 & 0.4 & 0.3 & 0.4 & 0.1 & 0.3 \\
\hline affection & 0.5 & 0.4 & 0.4 & 0.6 & 0.1 & 0.3 \\
\hline account & -0.1 & 0.1 & 0.4 & 0.3 & -0.1 & -0.2 \\
\hline not account & 0.3 & -0.2 & 0.5 & 0.3 & 0.1 & 0.2 \\
\hline dislike & -0.3 & -0.4 & -0.2 & -0.5 & -0.2 & 0.2 \\
\hline unreliability & -0.2 & -0.8 & -0.2 & -0.6 & -0.1 & -0.1 \\
\hline ignorance & -0.1 & -0.6 & -0.5 & -1.2 & -0.2 & -0.2 \\
\hline unpredictability & -0.4 & -0.6 & -0.5 & -0.7 & -0.1 & -0.2 \\
\hline
\end{tabular}

The correlation coefficient ( $r$ ) is equal to 0.939 . The interrelation between the studied features - a straight line. The tightness (strength) of the relationship on the cheddar scale is very high. The number of degrees of freedom (f) is 8 ; student's t-test is 7.730 . The critical value of student's t-test at a given number of degrees of freedom is 2.306. tobserved $>$ tcritical, the dependence of the characteristics is statistically significant $(p=0.000113)$. The equation of the pair-like linear regression: $\mathrm{y}=$ $975.63700+1.35094 * x$. The coefficient of determination $\mathrm{r} 2$ is equal to 0.882 (factorial characteristic $\mathrm{x}$ determines $88.2 \%$ of the variance in the dependent characteristic y). The average approximation error (characterizes the adequacy of the regression model) is $9.3 \%$.

4. To analyze changes in key indicators of changes in group dynamics and development of corporate culture in the student group, we used the author's questionnaire by A.V. Pesha. Group dynamics indicators were linked to key components of the organizational culture, after which they were analyzed.

The scope of variation is the difference between the maximum and minimum values of the feature of the primary series:

$$
\begin{aligned}
& R=X \max -X \min \\
& \mathrm{R}=5,3875-5,925=0,5375
\end{aligned}
$$$$
\text { Dispersion }
$$

The mean square deviation of the groups was 0.17

Each series value differs from the average value of 5.567 by no more than 0.17 .

This deviation of the variance indicates a slight difference in the perception of corporate culture by students of different groups and courses.

The scope of variation of the values of the primary series in groups after training the formation of corporate culture:

\section{$\mathrm{R}=7.5-5.35=2.15$}

The total variance in the six sample groups:

$$
\mathrm{D}=\sum(\mathrm{xi}-\mathrm{x}) 2 \mathrm{n}
$$

$\mathrm{D}=3.384 / 6=0.564$

The mean squared deviation (mean sample error) for the groups was $\sigma=\sqrt{ } \mathrm{D}=\sqrt{ } 0.564=0.75$

Each series value differs from the average value of 6.402 by no more than 0.75 .

This deviation of dispersion indicators indicates a greater dispersion of the values of perception of corporate culture components by students of different groups after training interaction.

The general analysis showed that variability (SS) within groups is significantly higher than between groups. The coefficient of intraclass correlation (group SS within /SS total) is equal to $37 \%$.

The analysis of the results in the experimental group showed that the dispersion based on intra-group variability led to much lower values than in the calculation based on the general variability (relative to the general average) ( $\mathrm{SS}$ is equal to 0.94 and 3.16, respectively). The reason for this is obviously the significant difference between the averages, and this difference between the averages explains the existing difference between the sums of squares. The F-criterion shows that the difference between the averages is statistically significant at 0.004 .

The analysis of variance of the indicators of perception of corporate culture components in the control group did not show statistically significant results.

Based methodologically on the interdependence of indicators of formation of group dynamics and corporate culture, the results of the analysis of variance, one can conclude about the positive impact of training activities on the formation of group integration. This fact is especially significantly stated by us in the process of observation in the final part of the training in the work of the student group on joint projects and their presentation. The process of joint activity became more open, the results of the work - more qualitative and operational. There was a high overall activity of the participants. Students themselves noted in their feedback the growth of mutual understanding and cooperation in the group, as well as the awareness of common values and views on the achievement of common group goals and contribution to the achievement of the goals of the University.

\section{Conclusion}

A. During the research, we have achieved the set objectives. Group dynamics influenced the formation of corporate values, goals, rules and norms of behavior, as well as the formation of cohesion in the student team. Since, the training formation of corporate culture was implemented in groups of students of the bachelor's program in "Personnel Management", for us it was important that future graduates were prepared to construct self-similar training events in the workforce as the leading group. The results of the training show the development of students' competencies in the management of organizational culture.

B. The study confirmed the hypothesis that the formation of a cohesive group of students in the process 
of training, corporate culture formation are possible in the construction of the training program taking into account the indicators of group dynamics.

\section{References}

1. L. I. Umansky, Questions of psychology staff students: nauch. proceedings (Publishing house of the pedagogical Institute, Kursk, 1972)

2. R. B Shaw, The Key to trust in organizations: Effectiveness, honesty, caring ( Business, Moscow, 2000)

3. Cartwright, A. Zander (eds.)., Group Dynamics. Research and Theory (Harper and Row, N. Y., 1968)

4. G. M Andreeva, Social psychology (Aspect Press, Moscow, 2001)

5. R. L. Krichevsky, The psychology of leadership: a Training manual (Statute, Moscow, 2007)

6. L. A. Petrovskaya, Theoretical and methodological problems of social and psychological training (MSU, Moscow, 1982)

7. L. I. Antsiferova, Psychological study of social personality development, 5-38 (1991)

8. A. S. Chernyshev, Organization and leadership in youth 319. groups: theory, experiment, practice: selected papers (Publishing house of KSU, Kursk, 2006)

9. E. N. Dyachkova, L. G. Hrebenyk, M. E. Ledovskaya, Science and education: new time 2, 205-212 (2016)

10. O. A. Kovaleva, Modern problems of science and education 2-2, 552-552 (2015)

11. A. Pelmenev and others, Engineering education 20, 178-187 (2016)

12. L. V. Baeva, Knowledge. Understanding. Skill 1, 8289 (2014)
13. Christian Gansuar, E. A. Neretina, Yu. V. Korokoshko, Integration of education 19(2), 22-30 (2015)

14. V. I. Ekimova Modern foreign psychology 4(2), 20-27 (2015)

15. N. F. Plotnikova, Formation of critical thinking of University students in the conditions of the command form of organization of training: monograph (Izd-vo Kazan. UN-TA, Kazan, 2015)

16. G. Bloom, D. Stevens, T. Wickwire, Journal of Applied Sport Psychology 15, 129-143 (2003)

17. I. Oplatka, International Journal of Leadership in Education: Theory and Practice 20, 517-524 (2017)

18. K. L. Michaelsen, M. Sweet, New Directions for Teaching and Learning. 8 December (2011)

19. M. A. Nazarenko, V. A. Petrov, V. V. Sidorin, Uspekhi sovremennogo estestvoznaniya 4, 171-172 (2013)

20. S. D. Reznik, M. V. Chernikovskaya, V. G. Kamburg, Proceedings of higher educational institutions. Volga region. Social science. 2 (2012)

21.X. Zhang, P. O. De Pablos, Q. Xu, Computers in Human Behavior 31, 491-498 (2014)

22. N. E. Ravikovich, Training team building. Objectives, diagnostic techniques, games (Genesis, Moscow, 2003)

23. P. R. Scholters, The Team Handbook. How to use Teams to Improve Quality (New York, 1986)

24. A. V. Pesha, Management approach to the formation of corporate culture of service sector organizations: dis. kand. Ekon. (Ekaterinburg, 2014)

25. A. B. Kupreychenko, Psychology of trust and distrust (Publishing house "Institute of psychology RAS", Moscow, 2008)

26. K. J. Chapman, M Meuter., D. Toy, L. WriteJournal of Management Education 30, 557-569 (2006) 